\title{
A Double-blind, Placebo-controlled, Randomized, Longitudinal Study on the Effects of a Plant-based Dietary Supplement on Nitric Oxide and Mitochondrial Metabolic Activity
}

\author{
Boris V. Nemzer ${ }^{1,2}$, Christoph Centner ${ }^{3}$, Noemi Wiessler ${ }^{3}$, Zb Pietrzkowski $^{4}$, John M. Hunter ${ }^{1}$, Bruno Fink ${ }^{5}$ \& \\ Daniel König ${ }^{3}$ \\ ${ }^{1}$ VDF FutureCeuticals, Inc., Momence, IL, USA \\ ${ }^{2}$ University Illinois at Urbana-Champaign, Urbana, IL, USA \\ ${ }^{3}$ Steinbeis Center for Health Promotion and Metabolic Research, Freiburg, Germany \\ ${ }^{4}$ VDF FutureCeuticals, Inc., Irvine, CA, USA \\ ${ }^{5}$ Noxygen Science Transfer \& Diagnostics GmbH, Elzach, Germany \\ Correspondence: Boris V. Nemzer, VDF FutureCeuticals, Inc., Momence, IL, USA. Tel: 1-815-507-1427. E-mail: \\ bnemzer@futureceuticals.com
}

Received: January 17, 2021

Accepted: February 11, $2021 \quad$ Online Published: February 24, 2021

doi:10.5539/jfr.v10n2p21

URL: https://doi.org/10.5539/jfr.v10n2p21

\begin{abstract}
During the past two decades, metabolic dysfunction and concomitant reduction-oxidation reaction (redox) imbalances (i.e., oxidative stress) have been suggested to be associated with numerous age-related chronic diseases. One profound result of metabolic imbalances is endothelial dysfunction, a pathophysiological condition that increases risk of downstream chronic disease consequences. Healthy endothelial function has been positively associated with elevated levels of circulating nitric oxide (NO). Consequently, a natural, plant-based material that may safely increase endogenous NO levels, reduce redox imbalance, and promote improved metabolic response could be of significant interest and benefit. In this first study of its kind, we conducted a longitudinal, randomized, double-blind, placebo-controlled study of S7, a proprietary polyphenol-rich fruit, vegetable, and herb-based material previously reported to reduce reactive oxygen species (ROS) and to increase NO. Specifically, we measured changes in real-time cellular generation of ROS and changes in levels of bioavailable NO (measured as circulating NOHb) in 42 overweight or slightly obese individuals who were recruited into one of three groups: placebo, $25 \mathrm{mg}$ of S7, and $50 \mathrm{mg}$ of S7. Results suggest that after 90 days of once-daily supplementation, the $25 \mathrm{mg}$ and $50 \mathrm{mg}$ S7 groups exhibited diminished mitochondrial ROS generation ( $\sim 54 \%$ and $\sim 75 \%$, respectively) compared to placebo, which exhibited a slight increase $(>12 \%)(p=0.049)$. Furthermore, circulating NOHb levels significantly increased in the $25 \mathrm{mg}$ and $50 \mathrm{mg} \mathrm{S7}$ groups $(33.87 \%$ and $53.43 \%$, respectively) compared to placebo ( $\mathrm{p}<0.001)$. Together, these results suggest that long-term daily supplementation of S7 may provide potential benefits related to healthy endothelial function and reduced mitochondrial dysfunction.
\end{abstract}

Keywords: endothelial dysfunction, metabolic syndrome, circulating NOHb, cellular metabolic activity, ROS, FMD, Alx 75\%, dietary supplement S7

\section{Introduction}

Obesity is a worldwide epidemic that has significant economic and health consequences. In 2008, an estimated $\$ 147$ billion U.S. dollars were spent on obesity-related healthcare costs (www.cdc.gov/obesity/data/adult). Additionally, obesity predisposes individuals to many diseases and disorders, including stroke, cardiovascular disease, diabetes, and certain types of cancer costs (www.cdc.gov/obesity/data/adult). In fact, for the first time, some models predict that children in America and Europe could have a shorter life expectancy than their parents (Olshansky et al., 2005). A large part of this risk is because obesity is a central factor in the development of Type 2 diabetes and metabolic syndrome, which have become one of the deadliest cardiovascular risk constellations (Reaven, 2011).

Metabolic syndrome is characterized by endothelial dysfunction, reduction-oxidation reaction (redox) imbalance, hypertension, impaired glucose tolerance, and dyslipidemia, many of which are coupled with the natural aging 
process (Reaven, 2011; Rask-Madsen \& Kahn, 2012; Yates, et al., 2012; Carrier, 2016; Spahis, Borys \& Levy, 2016; McCracken et al., 2018; Kotkowski et al., 2019; Vona et al., 2019). Given that the constellation of symptoms describing metabolic syndrome varies substantially, many researchers have sought physiological biomarkers capable of measuring widespread dysfunction. For example, redox processes pervade practically all fundamental processes, from bioenergetics to metabolism, making them ideal candidates because of their ability to have system-wide effects. Signaling molecules, such as nitric oxide $\left(\mathrm{NO}^{\bullet}\right)$ and superoxide radical $\left(\mathrm{O}_{2}{ }^{\bullet}\right)$, have fundamental implications in biology and represent biosignatures related to metabolic syndrome and its role in the development of subsequent pathology, ranging from cardiovascular disease to dementia (Coleman, 2001; Laroux et al., 2001; Korhonen et al., 2005; Stephan et al., 2017; Yuyun, Ng \& Ng, 2018). One of the mechanisms through which $\mathrm{NO}^{\bullet}$ serves as a marker of endothelial dysfunction is through its interaction with superoxide and the subsequent formation of further downstream reactive oxygen and nitrogen species (ROS/RNS) (Laight et al., 1998; Kojda \& Harrison, 1999; Zalba et al., 2001; Bauersachs \& Widder, 2008; Schulz, Gori \& Munzel, 2011). These are relevant for the cardiovascular system since the cardiovascular endothelial homeostasis relies on an equilibrium between these two factors. For example, decreases in $\mathrm{NO}^{\bullet}$ concomitant with increases in ROS cause endothelial dysfunction and increased risk of cardiovascular disease (Yuyun, $\mathrm{Ng} \& \mathrm{Ng}, 2018$ ), one of the most prevalent conditions associated with obesity and metabolic syndrome.

Furthermore, increased ROS production has been posited to be associated with the generation of adipokines. Adipokines are bioactive substances found in adipose tissue that induce generation of ROS (Fernández-Sánchez et al., 2011). In any event, increased ROS production also leads to diminished availability of $\mathrm{NO}^{\bullet}$ and endothelial dysfunction (Fernández-Sánchez et al., 2011). Thus, NO and ROS, when measured simultaneously, may serve as a robust indicator of underlying processes that significantly contribute to morbid outcomes in obesity and metabolic syndrome.

The role of ROS and NO in oxidative stress is expansive, and pivotal cellular mechanisms have been proposed. For example, mitochondrial dysfunction is associated with increased ROS formation in diabetics (Wu et al., 2018), while also being implicated as a leading factor in heart failure and obesity (Zhou \& Tian, 2018; de Mello, Costa, Engel \& Rezin, 2018). Interestingly, research has already suggested that combinations of polyphenols (i.e., colorful compounds commonly found in fruits and vegetables that have been shown to have protective biological effects) present in diets rich in fruits and vegetables may be of particular interest in connection with antioxidant properties (Han, Shen \& Lou, 2007; Mullen et al., 2011; Yashin et al., 2013; Hussain et al., 2016; Arulselvan et al. 2016; Sarubbo et al., 2018). In vitro, these compounds have demonstrated robust ROS scavenging capabilities while ex vivo studies have demonstrated their effectiveness at reducing oxidative stress (Niu et al., 2015; Serino \& Salazar, 2018; Nemzer et al., 2018). Additionally, a recent review suggests that polyphenols may improve mitochondrial function while also improving antioxidant capacity through their disruption of cellular senescence, a process in which cells become dysfunctional and secrete messengers, such as ROS (Serino, \& Salazar, 2018). Furthermore, flavonoids, one of the largest categories of polyphenols, have been postulated to increase $\mathrm{NO}^{\bullet}$, although the exact mechanisms are not yet well understood (Duarte et al., 2014).

In this study, we utilized technological advancements related to the assessment of $\mathrm{NO}^{\bullet}$ and $\mathrm{ROS}$ in order to conduct a double-blind, placebo-controlled, longitudinal study designed to determine the physiological effects of S7, a plant-based, phenolic-rich dietary supplement. Contributing to the novelty of the study, we used scientifically well-recognized electron spin resonance (ESR) spectroscopy (Hawkins \& Davies, 2014; Dikalov, Griendling \& Harrison, 2007) for direct real-time observation of the physiological levels of cellular, mitochondrial, peroxidaseand NADPH-oxidase dependent ROS formation in whole blood (Nemzer et al., 2018) and for measurement of concentrations of circulating bioavailable $\mathrm{NO}^{\bullet}(\mathrm{NOHb})$ that reflects the relative extent of endothelial function (Fink, Dikalov \& Fink, 2006). Additionally, we assessed mitochondrial function using a technique previously developed by our laboratory (Nemzer et al., 2018). Advances in instrumentation (a bench-top ESR spectrometer NOXYSCAN System) provided an opportunity to uniquely investigate the bioactivity of S7 on overweight or slightly obese older adults who potentially have an increased susceptibility to metabolic imbalances. S7 is a proprietary formulation of botanical materials high in phytochemicals (Table 1). 
Table 1. Phytochemical composition of the nutritional supplement S7 per 25 and $50 \mathrm{mg}$ serving dose

\begin{tabular}{lllll}
\hline Phytochemical components & Units & $25 \mathrm{mg}$ & $50 \mathrm{mg}$ & Amount (\%) \\
\hline Catechins & $\mathrm{mg}$ & 9.2 & 18.4 & 36.8 \\
Chlorogenic acids & $\mathrm{mg}$ & 6.6 & 13.2 & 26.2 \\
EGCG & $\mathrm{mg}$ & 4.6 & 9.2 & 18.4 \\
Curcumin & $\mathrm{mg}$ & 1.1 & 2.1 & 4.2 \\
Caffeine & $\mathrm{mg}$ & 0.9 & 1.7 & 3.4 \\
Anthocyanins & $\mu \mathrm{g}$ & 26.3 & 52.5 & 0.001 \\
Trigonelline & $\mu \mathrm{g}$ & 27.6 & 55.1 & 0.001 \\
Vitamin C & $\mathrm{ng}$ & 2.6 & 5.2 & $1 \times 10^{-4}$ \\
Vitamin E & $\mathrm{ng}$ & 0.075 & 0.15 & $3 \times 10^{-6}$ \\
\hline
\end{tabular}

Given that previous clinical trials have suggested that acute nutraceutical interventions may be effective in attenuating the generation of ROS as well as atherosclerotic events and disease progression (Nemzer, Fink \& Fink, 2014; Nemzer et al., 2018) this current longitudinal assessment of $\mathrm{NO}^{\circ}$, ROS levels, and mitochondrial function represents a logical next-step contribution to the literature. We hypothesized that long-term supplementation of S7 would lead to reduced $\mathrm{ROS}$ and increased $\mathrm{NO}^{\bullet}$ with concurrent improvement in mitochondrial function.

\section{Methods}

This study was designed to be a 90-day, randomized, longitudinal, double-blind, placebo-controlled investigation of the long-term effects of S7, a proprietary, plant-based dietary supplement that is the hypothesized to new effect of long-term supplementation on NO/ROS.

As such, we sought to recruit individuals who were overweight or slightly obese and therefore at risk for compromised ability to maintain healthy oxidation-reduction levels, but who were not diabetic or otherwise specifically diagnosed with any metabolic condition. The study protocol was registered with and approved by the ethics committee of the Federal Medical Association of Baden-Wuerttemberg (F-2017-030) and was conducted according to provisions of German law, ICH-GCP guidelines, and the general principles of the original World Medical Association's Declaration of Helsinki.

\subsection{Participants}

Forty-eight participants were initially recruited and randomly assigned, after matching for age and gender, to one of three groups: placebo ("placebo"), $25 \mathrm{mg}$ S7 (“25mg”), or 50mg S7 (“50mg"). Participants were initially screened during a baseline laboratory visit, at which time they were told about the study, provided informed consent, and had basic health parameters collected to determine eligibility for the study. To be eligible for the study, participants 1) had to be between 40 and 70 years of age, 2) had to be overweight BMI $>25$ or slightly obese BMI $\leq 34.9,3$ ) had to be willing to refrain from making any lifestyle changes or altering their diet/exercise regimen for the duration of the study (Fitbit tracker has been used to monitor the exercise level of participants), and 4) had to have an HbA1c < 6.5\%. Other exclusion criteria included: smokers, diagnosed Type I or Type II diabetics, any liver/kidney impairments, acute or chronic psychiatric, gastrointestinal, pulmonary, renal, neurological, or cardiovascular disorders, known allergies to foods or other ingredients, used supplements or vitamins, or were taking medications known to affect endothelial function (e.g., ACE-inhibitors or $\beta$-blockers). Additionally, participants were excluded if they participated in another clinical trial within 90 days of enrolling. Five participants dropped out of the study, for an attrition rate of $10.4 \%$, and 1 participant was excluded from further analysis because they did not meet inclusion criteria $(\mathrm{HbA} 1 \mathrm{c}>6.5 \%)$, leaving a total of 42 participants $(\mathrm{n}=13,16$, and 13 for the placebo, 25mg, and 50mg groups, respectively). Groups were equivalent on key health measures (Table 2). 
Table 2. Demographic and health information for the three study groups, and univariate ANOVA results (with 'group' as a fixed factor and each variable as the dependent measure) confirming that the groups did not differ on any parameter at $\mathrm{T} 1$. Data represented in the table are mean \pm SEM

\begin{tabular}{llllll}
\hline & $\begin{array}{l}\text { Placebo }(\mathrm{n}=13, \\
8 \text { women })\end{array}$ & $\begin{array}{l}25 \mathrm{mg}(\mathrm{n}=16, \\
8 \text { women })\end{array}$ & $\begin{array}{l}50 \mathrm{mg}(\mathrm{n}=13, \\
7 \text { women })\end{array}$ & $\begin{array}{l}\text { Group } \\
\text { Differ. (F) }\end{array}$ & $\begin{array}{l}\text { Group Differ. } \\
(\text { Sig. })\end{array}$ \\
\hline Age & $57.8 \pm 1.4$ & $58.4 \pm 1.4$ & $57.7 \pm 1.7$ & 0.14 & 0.88 \\
Waist $(\mathrm{cm})$ & $109.5 \pm 2.8$ & $110.3 \pm 1.8$ & $106.2 \pm 2.6$ & 0.39 & 0.68 \\
Weight $(\mathrm{kg})$ & $89.5 \pm 3.2$ & $92.9 \pm 3.1$ & $92.7 \pm 3.5$ & 0.72 & 0.50 \\
BMI & $31.5 \pm 1.0$ & $31.8 \pm 1.0$ & $31.4 \pm 0.6$ & 0.26 & 0.78 \\
HDL (mg/dl) & $53.6 \pm 3.1$ & $59.7 \pm 4.4$ & $55.9 \pm 3.5$ & 0.89 & 0.42 \\
Triglyceride $(\mathrm{mg} / \mathrm{dl})$ & $136.7 \pm 14.0$ & $179.9 \pm 47.6$ & $184.7 \pm 19.3$ & 0.48 & 0.62 \\
Fasting glucose (mg/dl) & $88.9 \pm 2.2$ & $90.8 \pm 1.8$ & $92.0 \pm 2.4$ & 0.12 & 0.89 \\
sBP (mmHg) & $138.5 \pm 4.1$ & $137.6 \pm 4.7$ & $142.4 \pm 4.9$ & 0.15 & 0.87 \\
dBP (mmHg) & $89.3 \pm 2.4$ & $87.5 \pm 2.5$ & $88.8 \pm 2.1$ & 0.71 & 0.50 \\
HR (bit/min) & $66.1 \pm 2.1$ & $66.8 \pm 2.8$ & $63.8 \pm 2.7$ & 0.34 & 0.72 \\
CMA (nmol/sec) & $282.1 \pm 8.4$ & $277.6 \pm 9.5$ & $275.8 \pm 8.1$ & 0.07 & 0.93 \\
NOHb (nmol) & $77.4 \pm 6.6$ & $86.2 \pm 6.4$ & $97.8 \pm 6.4$ & 0.33 & 0.72 \\
\hline
\end{tabular}

\subsection{Study Design}

After the initial consenting visit, participants were sent home with instructions to return in a fasted condition for Time 1 (T1) assessments, which were performed within two days from the initial contact. T1 assessments included a general health evaluation performed by a study physician, cognitive assessments, a venous capillary blood draw, and cardiovascular parameters, which were recorded using the AngioDefender (Everist Health, USA) and the SphygmoCor XCEL (AtCor Medical Inc., USA). At the end of the T1 visit, study participants received encapsulated materials corresponding to their group assignment (placebo, 25mg S7, or 50mg S7), and given explicit instructions regarding ingestion. Specifically, participants were instructed to take 1 capsule every morning with food at approximately the same time every day. After the 90-day study period, participants were scheduled for Time 2 (T2) assessments, which were identical to T1.

\subsection{Assays}

\subsubsection{Cellular Metabolic Activity (CMA)}

The extended CMA assay, developed by Noxygen Science Transfer \& Diagnostics GmbH (Elzach, Germany), is based upon the monitoring of cellular ROS generation, as well as mitochondrial, peroxidase $\left(\mathrm{H}_{2} \mathrm{O}_{2}\right)$, and NADPH-oxidase $\left(\mathrm{O}_{2}{ }^{-}\right)$dependent generation of ROS (patent pending). The CMA assay is performed using a bench-top ESR spectrometer equipped with a Temperature and Gas Controller (Noxygen Science Transfer \& Diagnostics GmbH, Germany) and a permeable cell membrane spin probe $(\mathrm{CMH}, 200 \mu \mathrm{M})$. For the measurement of extended CMA we added superoxide dismutase SOD $(50 \mathrm{U} / \mathrm{ml})$ or catalase $(50 \mathrm{U} / \mathrm{ml})$ or Antimycin A $(10 \mu \mathrm{M})$ to a portion of the freshly drawn capillary blood $(36 \mu \mathrm{L})$ diluted with the same volume Krebs-Hepes buffer containing $100 \mathrm{U} / \mathrm{ml}$ heparin and $10 \mu \mathrm{M}$ of oxygen label in order to perform all four types of analyses under controlled temperature and oxygen concentration $\left(\mathrm{t}=37^{\circ} \mathrm{C}, \mathrm{pO} 2=110 \mathrm{~mm} / \mathrm{Hg}\right)($ Nemzer, Centner, Zdzieblik, Fink, Hunter, \& König, 2018). The addition of an oxygen label (NOX-15.1 - $5 \mu \mathrm{M}$ ) to the blood sample allowed for assessment of oxygen concentrations, as well as cellular and mitochondrial oxygen consumption (Komarov et al., 2012).

\subsubsection{Bioavailable Nitric Oxide Concentration ( $\mathrm{NOHb}$ )}

Venous blood was taken from a cubital vein using vacutainer containing L-Heparin without upper arm compression and was transferred into a $1 \mathrm{ml}$ insulin syringe and spun down $(1600 \mathrm{x} \mathrm{g})$ for 5 minutes at room temperature. Afterward, the sample was frozen in liquid nitrogen and kept at $-80^{\circ} \mathrm{C}$. Measurement of $\mathrm{NOHb}$ content was performed at $77^{\circ} \mathrm{K}$ with liquid nitrogen-filled quartz finger dewar. ESR spectrometer (NOXYSCAN equipped with a newly designed cavity and operating at $86 \mathrm{kHz}$ field modulation) was used to collect ESR spectra at the $9.7 \mathrm{GHz} \mathrm{X}$ band using the settings described in Fink et al., 2006 (Fink, Dikalov, \& Fink, 2006). The amount of detected NOª second crucial signaling molecule of vascular physiology (Dikalov, \& Fink, 2005; Pisaneschi et al. 2012) was determined by comparison to the calibration curve for the intensity of the EPR signal of erythrocytes that were treated with known concentrations of nitrite $(1-25 \mu \mathrm{M})$. 


\subsection{Chemicals}

The spin probes 1-hydroxy-3-methoxycarbonyl-2.2.5.5-tetramethyl-pyrrolidine (CMH), 1-hydroxy-4-phosphono-oxy-2.2.6, the metal chelators deferoxamine (DF) and diethyldithiocarbamate (DETC), Krebs-Hepes buffer (KHB), and the oxygen label NOX-15.1 were obtained from Noxygen Science Transfer \& Diagnostics (Elzach, Germany). All other chemicals and reagents used were of analytical grade and were purchased from Sigma-Aldrich (St. Louis, MO. USA) unless otherwise specified.

\subsection{Analytic Plan}

Prior to performing statistical analyses, descriptive statistics were determined for each dependent variable and normality was assessed. Outliers were determined using a Tukey fences approach $\left(\left(\mathrm{Q}_{1}-1.5^{*}(\mathrm{IQR})\right)\right.$ and $\left(\mathrm{Q}_{3}+1.5^{*}(\mathrm{IQR})\right)$, where $\mathrm{Q}_{1}$ is the first quartile, and $\mathrm{Q}_{3}$ is the third quartile). Outliers exceeding these boundaries were excluded from analysis. Repeated measures ANOVAs were performed with group as the between-subjects factor and dependent measurements at T1 and T2 as within-subjects factors. Post-hoc comparisons were evaluated for significant effects. In the case of interactions, univariate ANOVAs were performed to determine the nature of the interaction to establish appropriate inferences. Statistical significance was determined at the $p<0.05$ level.

\section{Results}

\subsection{CMA}

\subsubsection{Mitochondrial CMA}

Descriptive statistics were determined for each group and each time point. Two participants were excluded from the analysis because of missing data, and 1 outlier was determined from the $50 \mathrm{mg}$ group, leaving group sizes of $n=13$, 15, and 11 (placebo, 25mg, 50mg, respectively). A repeated-measures ANOVA was conducted with the two-time measurements (T1, T2) as within-subjects factors, and group as a between-subjects factor. Results indicated a significant main effect of time $\left(F(1,36)=7.252, p=0.011\right.$, partial $\left.\eta^{2}=0.168\right)$ and a significant time by group interaction $\left(F(2,36)=3.313, p=0.048\right.$, partial $\left.\eta^{2}=0.155\right)$ ( Figure 1). A main effect of group was not found $(F(2,36)$ $=1.311, p=0.282$ ). To better understand the interaction, we conducted univariate ANOVAs on the T1 and T2, separately. There were no significant differences at $\mathrm{T} 1(F(2,36)=0.236, p=0.791)$. T2 differences were significant $(F(2,36)=3.285, p=0.049)$, with least significant difference (LSD) posthoc comparisons suggesting that the placebo group was significantly different from both the $25 \mathrm{mg}$ group $(p=0.046)$ and the $50 \mathrm{mg}$ group $(p=0.025)$. The two S7 groups were not significantly different from each other $(p=0.663)$. Given these results and that the direction of mitochondrial ROS generation differed between placebo and S7 groups (i.e., placebo increased over 12\%, while the $25 \mathrm{mg}$ and 50mg S7 groups decreased almost 54\% and over 75\%, respectively), it is likely that the interaction was driven by $\mathrm{S} 7$ supplementation.

A.

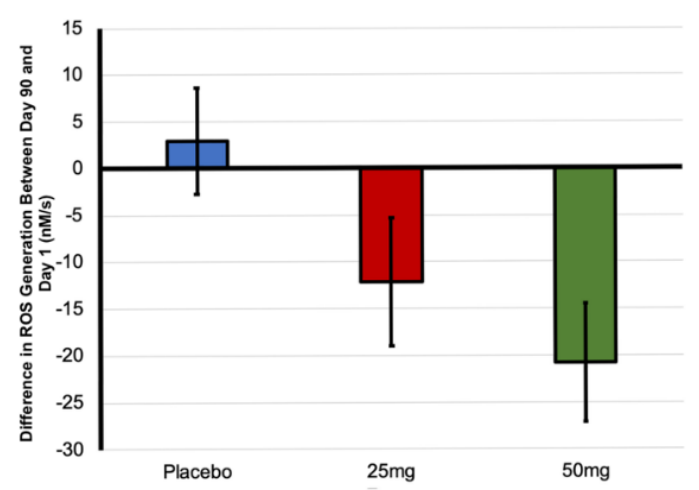

\section{Long-term Effects of S7 on Mitochondrial CMA}

B.

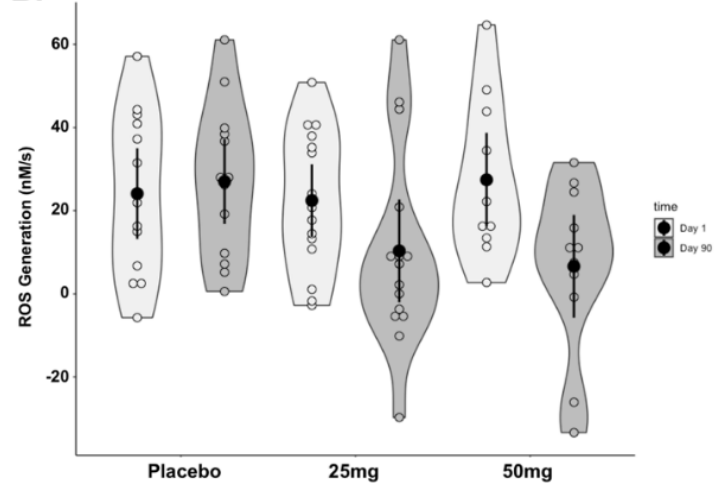

Figure 1. A) Bar graph representing the differences between T1 (Day 1) and T2 (Day 90) (M \pm SEM). B) Violin plots demonstrating the raw data. Violin plots were created with open-source software ggplot2 to visualize the distribution and kernel probability density of the data within each group at each timepoint. Black circles with connected lines represent the $\mathrm{M} \pm 2 * \mathrm{SEM}$ 


\subsection{2 $\mathrm{H}_{2} \mathrm{O}_{2}$ CMA}

Descriptive statistics were determined for each group and each time point. Two participants were excluded for missing data, and two outliers were determined, leaving group sizes of $n=13,14$, and 11 (placebo, 25mg, 50mg, respectively). A repeated-measures ANOVA indicated no effect of time $(F(1,35)=0.824, p=0.370)$, nor was there a time by group interaction $(F(2,35)=0.092, p=0.912)$. There was, however, a significant main effect of group $(F(2$, $35)=3.393, p=0.045$, partial $\eta^{2}=0.162$ ). LSD post-hoc comparisons indicated that the placebo group was significantly different from both the $25 \mathrm{mg}(p=0.026)$ and the $50 \mathrm{mg}(p=0.038)$ groups. The $25 \mathrm{mg}$ and $50 \mathrm{mg}$ groups were not different from each other $(p=0.969)$. These effects are likely driven by qualitative differences in baseline measures, as all three groups demonstrated similar decreases over time $(16.38 \%, 7.92 \%$, and $17.36 \%$ for placebo, $25 \mathrm{mg}$, and 50mg, respectively).

\subsubsection{NADPH-oxidase CMA}

Descriptive statistics were determined for each group and each timepoint. Two participants were excluded for missing data, and one outlier was determined, leaving group sizes of $n=13,15$, and 11 (placebo, 25mg, 50mg, respectively). A repeated-measures ANOVA indicated no effect of time on NADPH-oxidase ROS generation $(F(1,36)$ $=0.918, p=0.344)$, no effect of group $(F(2,36)=0.781, p=0.465)$, and no group by time interaction $(F(2,36)=$ $2.396, p=0.105)$.

\section{$3.2 \mathrm{NOHb}$}

Descriptive statistics were determined for each of the two timepoints and data were checked for normality. One participant's data was incomplete, and 1 outlier was determined from the $50 \mathrm{mg}$ group, leaving group sizes of $n=13$, 15 , and 12 (placebo, $25 \mathrm{mg}, 50 \mathrm{mg}$, respectively). A repeated-measures ANOVA was conducted with the $2 \mathrm{NOHb}$ measurements (T1 and T2) as within-subjects factors and group as a between-subjects factor. Results indicated a significant effect of time $\left(F(1,37)=36.629, p<0.001\right.$, partial $\left.\eta^{2}=0.497\right)$ (Figure 2). Additionally, there was a time by group interaction $\left(F(2,37)=7.520, p=0.002\right.$, partial $\left.\eta^{2}=0.289\right)$, as well as a main effect of group $(F(2,37)=$ $10.559, p<0.001$, partial $\eta^{2}=0.365$ ). LSD post-hoc comparisons revealed significant differences between all three groups (placebo $<25 \mathrm{mg}, p=0.024$; placebo $<50 \mathrm{mg}, p<0.001 ; 25 \mathrm{mg}<50 \mathrm{mg}, p=0.019$ ). To determine the nature of the interaction, we conducted univariate ANOVAs at T1 and T2. Results indicated that there were no differences at $\mathrm{T} 1(F(2,37)=1.595, p=0.216)$, but, and as expected, there were differences at $\mathrm{T} 2(F(2,37)=15.792, p<0.001$, partial $\left.\eta^{2}=0.461\right)$. LSD post-hoc tests revealed that placebo was significantly different from the $25 \mathrm{mg}(p=0.005)$ and 50mg $(p<0.001)$ groups. Additionally, the $25 \mathrm{mg}$ group was significantly different from the 50mg group $(p=$ 0.006). Specifically, the placebo group exhibited the least NOHb concentration (M \pm SEM: 84.354 \pm 7.961 ) compared to the $25 \mathrm{mg}$ group ( $\mathrm{M} \pm \mathrm{SEM}$ : $116.453 \pm 7.411)$ and the 50mg group (M $\pm \mathrm{SEM}: 148.917 \pm 8.286)$. Because the groups were not significant at $\mathrm{T} 1$ but exhibited differences at T2, these data provide strong support that the effects observed on NOHb concentration are being driven by S7. Specifically, over the 90 days, NOHb concentration increased $6.67 \%$ for placebo, $33.87 \%$ for the $25 \mathrm{mg}$ group, and $53.43 \%$ for the $50 \mathrm{mg}$ group.

A.

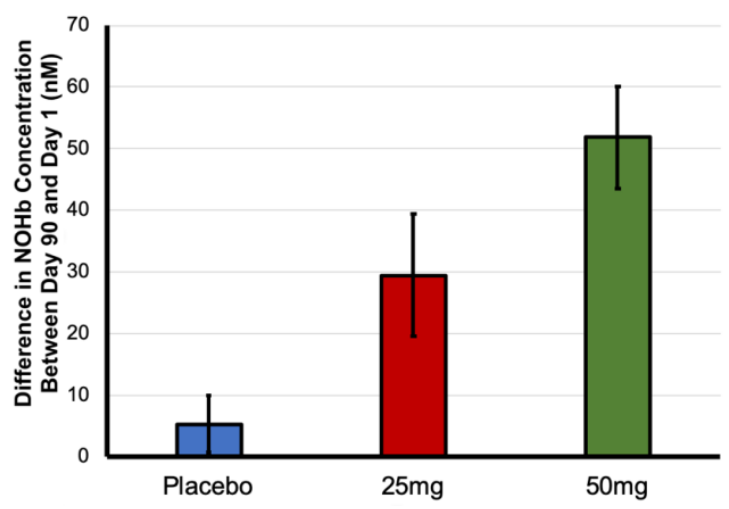

\section{Long-term Effects of S7 on NOHb}

B.

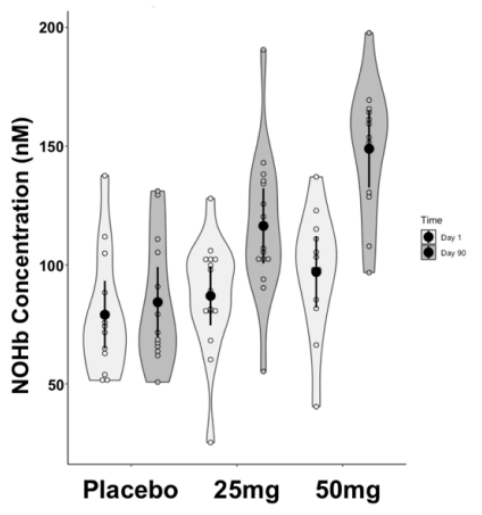

Figure 2. A) Bar graph representing the differences between T1 (Day 1) and T2 (Day 90) (M \pm SEM). B) Violin plots demonstrating the raw $\mathrm{NOHb}$ data. Violin plots were created with open-source software ggplot2 to visualize the 
distribution and kernel probability density of the data within each group at each timepoint. Black dots with connected lines represent the $\mathrm{M} \pm 2 * \mathrm{SEM}$

\section{Discussion}

Here, we provide evidence supporting our hypotheses that long-term administration of S7, a dietary supplement rich in phytochemicals, reduces ROS and increases $\mathrm{NO}^{\bullet}$ in overweight or slightly obese participants susceptible to metabolic dysbalance. The observed multifaceted effects of S7 are in agreement with the healthy redox balance hypothesis (Dröge, 2002), which consequently affects $\mathrm{NO}^{\bullet}$ bioavailability. Given the composition of S7, there are several potential ingredients that may contribute to the underlying mechanisms driving these effects. Specifically, catechins, which represents $36.8 \%$ of the material, are polyphenols that have been shown to have protective health benefits through reductions in ROS (Ruidavets et al., 2000; Xiangxin et al., 2002; Hofmann \& Sonenshein, 2003; Ohga et al., 2009; Hazafa et al., 2019; Wang et al., 2019). Additionally, S7 has a high percentage of chlorogenic acids (26.2\%), that have been shown to decrease ROS and increase ATP production in cells (Youn et al., 2019). These results converge with previous accounts from our lab and others demonstrating that catechins ((-)-epigallocatechin, "EGC", (-)-epigallocatechin-3-gallate, "EGCG") and chlorogenic acids may modify ROS generation (Manach et al., 2005; Nemzer et al., 2018). impact the activity of antioxidative enzymes, reduce lipid peroxidation, promote the expression of p53, p21 and NF- $\mathrm{kB}$ (Hofmann \& Sonenshein, 2003), and reduce the accumulation of cholesterol in the vessel wall, thus inhibiting development of atherosclerosis (Xiangxin et al., 2002). Furthermore, other lesser ingredients of S7, such as curcumin, for example, have been reported to modulate redox status over the (NRF2) pathway (Shen et al., 2015), with subsequent increases of intracellular Superoxide Dismutase, (SOD) expression, thereby dismutating superoxide radicals into hydrogen peroxide. This is a signaling pathway that further/also leads to expression of Endothelial Nitric Oxide Synthase (eNOS). Such effects consequently serve to increase the bioavailability of $\mathrm{NO}^{\bullet}$ (Umemura, 2006; Joe \& Lokesh, 1994). The observed multifaceted effects of S7's various compounds seem to be potentially in accord with the components of a healthy redox balance hypothesis (Dröge, 2002). Further research is necessary to confirm this theoretical possibility.

This study confirmed the long-term antioxidative properties of S7 via the reduction of mitochondrial ROS generation concomitant with NOHb increases. Specifically, we observed a greater than $33 \%$ increase in NOHb in the $25 \mathrm{mg} \mathrm{S7}$ group, and a greater than 53\% increase in the 50mg S7 group, as compared to placebo, that had a modest $6.67 \%$ increase. The mitochondrial ROS results complemented this pattern wherein placebo increased mitochondrial ROS by approximately $12 \%$ while the $25 \mathrm{mg}$ and $50 \mathrm{mg}$ groups demonstrated substantial decreases of over $54 \%$ and $75 \%$, respectively. Thus, we conclude that S7, when administered over a 90 -day period, increases levels of bioavailable $\mathrm{NO}^{\bullet}$, potentially through normalization of mitochondrial ROS generation. Given that the regulation of vascular tone, endothelial function, and cardiovascular function depend heavily on the bioavailability of NO (Stephan et al., 2017; Yuyun, $\mathrm{Ng} \& \mathrm{Ng}, 2018$ ), these results may have important implications for various clinical health outcomes including athletic performance. Although we cannot yet confirm the causal relationship between $\mathrm{NOHb}$ and mitochondrial ROS generation in this current study, future studies will investigate other potential mediators and mechanisms through which $\mathrm{NO}^{\bullet}$ increases.

The current study has some limitations. First, the sample size is small, which reduces the power to detect effects. Future studies should be more highly powered in order to detect more subtle effects, which may shed light on other potential mechanisms related to the observed antioxidant properties of S7. Second, we used a participant sample that was overweight or slightly obese and therefore potentially on the cusp of metabolic dysbalance. Thus, we cannot conclude that these results would generalize to other populations of interest, including different age groups. As such, additional studies investigating S7 in other populations would provide intriguing lines of inquiry.

\section{Conclusion}

In conclusion, for the first time we were able to measure the ability of S7, a polyphenol-rich botanical dietary supplement, to positively increase levels of bioavailable $\mathrm{NO}^{\bullet}$ and to reduce levels of mitochondrial ROS in a sample of older, overweight or slightly obese adults. These results suggest that S7 has significant potential to improve endothelial function, to increase circulating $\mathrm{NO}^{\bullet}$ concentrations, to support healthier redox status, and to promote other positive health outcomes through antioxidant effects that are not system specific. Future studies should examine the effects of S7 on other conditions for which dysregulated redox signalling is a hallmark feature (i.e., sports performance and recovery, or specific metabolic or cardiovascular conditions).

\section{Acknowledgments}

Herewith we thank Dr. Jennifer Robinson of Auburn University for independent statistical analysis and critical 
review of this manuscript. Also, we would like to thank Ms. Patricia Dufner for their excellent technical assistance.

\section{References}

Arulselvan, P., Fard, M. T., Tan, W. S., Gothai, S., Fakurazi, S., Norhaizan, M. E., \& Kumar, S. S. (2016). Role of antioxidants and natural products in inflammation. Oxidative Medicine and Cellular Longevity, 15. https://doi.org/10.1155/2016/5276130

Bauersachs, J. \& Widder, J. D. (2008). Endotheil dysfunction in heart failure, Pharmacological Reports, 60, 119-126.

Carrier, A. (2016). Metabolic syndrome and oxidative stress: a complex relationship. Antioxidants and Redox Signaling, 26, 429-431. https://doi.org/10.1089/ars.2016.6929

Coleman, J. W. (2001). Nitric oxide in immunity and inflammation. International Immunopharmacology, 1 , 1397-1406. https://doi.org/10.1016/S1567-5769(01)00086-8

Dikalov, S., Griendling, K. K., \& Harrison, D. G. (2007). Measurement of reactive oxygen species in cardiovascular studies. Hypertension, 49, 717-727. https://doi.org/10.1161/01.HYP.0000258594.87211.6b

Dikalov, S., \& Fink, B. (2005). ESR Techniques for the Detection of Nitric Oxide In Vivo and in Tissues. Methods in Enzymology, 396, 597-610. https://doi.org/10.1016/S0076-6879(05)96052-7

Dröge, W. (2002). Free radicals in the physiological control of cell function. Physiological Reviews, 82, 47-95. https://doi.org/10.1152/physrev.00018.2001

Duarte, J., Francisco, V., \& Perez-Vizcaino, F. (2014). Modulation of nitric oxide by flavonoids. Food and Function, 5, 1653-1668. https://doi.org/10.1039/c4fo00144c

Fernández-Sánchez, A., Madrigal-Santillán, E., Bautista, M., Esquivel-Soto, J., Morales-González, Á., Esquivel-Chirino, C., ... Morales-González, J. A. ( 2011). Inflammation, oxidative stress, and obesity. Interantional Journal of Molecular Sciences, 12, 3117-3132. https://doi.org/10.3390/ijms12053117

Fink, B., Dikalov, S., \& Fink, N. (2006). ESR techniques for the detection of nitric oxide in vivo as an index of endothelial function. Pharmacological Reports, 58, 8.

Han, X., Shen, T., \& Lou, H. (2007). Dietary polyphenols and their biological significance. Interantional Journal of Molecular Science, 8, 950-988. https://doi.org/10.3390/i8090950

Hawkins, C. L., \& Davies, M. J. (2014). Detection and characterisation of radicals in biological materials using EPR methodology. Biochimica Biophysica Acta (BBA) - General Subjects, 1840, 708-721. https://doi.org/10.1016/j.bbagen.2013.03.034

Hazafa, A., Rehman, K. U., Jahan, N., \& Jabeen, Z. (2019). The role of polyphenol (flavonoids) compounds in the treatment of cancer cells. Nutrition and Cancer, 9, 1-12. https://doi.org/10.1080/01635581.2019.1637006

Hofmann, C. S., \& Sonenshein, G. E. (2003). Green tea polyphenol epigallocatechin-3 gallate induces apoptosis of proliferating vascular smooth muscle cells via activation of p53. The Fedearation of American Societies of Experimental Biology Journal, 17, 702-704. https://doi.org/10.1096/fj.02-0665fje

Hussain, T., Tan, B., Yin, Y., Blachier, F., Tossou, M. C. B., \& Rahu, N. (2016). Oxidative stress and inflammation: what polyphenols can do for us? Oxidative Medicine and Cellular Longevity, 9. https://doi.org/10.1155/2016/7432797

Joe, B., \& Lokesh, B. (1994). Role of capsaicin, curcumin and dietary $n-3$ fatty acids in lowering the generation of reactive oxygen species in rat peritoneal macrophages. Biochimica Biophysica Acta, 1224, 255-263. https://doi.org/10.1016/0167-4889(94)90198-8

Komarov, D. A., Dhimitruka, I., Kirilyuk, I. A., Trofimiov, D. G., Grigor'Ev, I. A., Zweier, J. L., \& Khramtsov, V. V. (2012). Electron paramagnetic resonance monitoring of ischemia-induced myocardial oxygen depletion and acidosis in isolated rat hearts using soluble paramagnetic probes. Magnatic Resonance in Medical Sciences, 68, 649-655. https://doi.org/10.1002/mrm.23251

Kotkowski, E., Price, L. R, Franklin, C., Salazar, M., Woolsey, M., DeFronzo, R. A., Blangero, J., Glahn, D. C., \& Fox, P. T. (2019). A neural signature of metabolic syndrome. Human Brain Mapping, 40, 3575-3588. https://doi.org/10.1002/hbm.24617

Kojda, G., \& Harrison, D. (1999). Interactions between NO and reactive oxygen species: pathophysiological 
importance in atherosclerosis, hypertention, diabetes and heart failure. Cardiovascular Research, 43, 652-671. https://doi.org/10.1016/S0008-6363(99)00169-8

Korhonen, R., Lahti, A., Kankaanranta, H., \& Moilanen, E. (2005). Nitric oxide production and signaling in inflammation. Current Drug Targets - Inflammation \& Allergy, 4, 471-479. https://doi.org/10.2174/1568010054526359

Laight, D. W., Kaw, A. V., Carrier, M. J., \& Anggard, E. E. (1998). Interaction between superoxide anion and nitric oxide in the regulation of vascular endothelial function. British Journal of Pharmacology, 124, 238-244. https://doi.org/10.1038/sj.bjp.0701814

Laroux, F. S., Pavlick, K. P., Hines, I. N., Kawachi, S., Harada, H., Bharwani, S., ... Grisham, M. B. (2001). Role of nitric oxide in inflammation. Acta Physiologica Scandinavica, 173, 113-118. https://doi.org/10.1046/j.1365-201X.2001.00891.x

Manach, C., Williamson, G., Morand, C., Scalbert, A., \& Rémésy, C. (2005). Bioavailability and bioefficacy of polyphenols in humans. I. review of 97 bioavailability studies. American Journal of Clinical Nutrition, 81, 230S-242S. https://doi.org/10.1093/ajcn/81.1.230S

McCracken, E., Monaghan, M., \& Sreenivasan, S. (2018). Pathophysiology of the metabolic syndrome. Clinics in Dermatology, 36, 14-20. https://doi.org/10.1016/j.clindermatol.2017.09.004

de Mello, A. H., Costa, A. B., Engel, J. D. G., \& Rezin, G. T. (2018). Mitochondrial dysfunction in obesity. Life Science, 192, 26-32. https://doi.org/10.1016/j.lfs.2017.11.019

Mullen, W., Nemzer, B., Ou, B., Stalmach, A., Hunter, J., Clifford, M. N., \& Combet, E. (2011). The Antioxidant and chlorogenic acid profiles of whole coffee fruits are influenced by the extraction procedures. Journal of Agricultural and Food Chemistry, 59, 3754-3762. https://doi.org/10.1021/jf200122m

Nemzer, B. V., Fink, N., \& Fink, B. (2014). New insights on effects of a dietary supplement on oxidative and nitrosative stress in humans. Food Science and Nutrition, 2, 828-839. https://doi.org/10.1002/fsn3.178

Nemzer, B. V., Centner, C., Zdzieblik, D., Fink, B., Hunter, J. M., \& König, D. (2018). Oxidative stress or redox signalling - new insights into the effects of a proprietary multifunctional botanical dietary supplement. Free Radical Research, 52, 362-372. https://doi.org/10.1080/10715762.2017.1390228

Niu, L., He, X-H., Wang, Q-W., Fu, M-Y., Xu, F., Xue, Y., Wang, Z-Z., \& An, X-J. (2015). Polyphenols in regulation of redox signaling and inflammation during cardiovascular diseases. Cellular Biochemistry and Biophysics, 72, 485-494. https://doi.org/10.1007/s12013-014-0492-5

Ohga, N., Hida, K., Hida, Y., Muraki, C., Tsuchiya, K., Matsuda, K., Ohiro, Y., Totsuka, Y., \& Shindoh, M. (2009). Inhibitory effects of epigallocatechin-3 gallate, a polyphenol in green tea, on oumor-associated endothelial cells and endothelial progenitor cells. Cancer Science, 100, 1963-1970.

https://doi.org/10.1111/j.1349-7006.2009.01255.x

Olshansky, S. J., Passaro, D. J., Hershow, R. C., Layden, J., Carnes, B. A., Brody, J., ... Ludwig, D. S. (2005). A potential decline in life expectancy in the United States in the 21st Century. New England Journal of Medicine, 352, 1138-1145. https://doi.org/10.1056/NEJMsr043743

Prevention, C. F. D. C. A. (2019). Overweight \& Obesity. Retrieved from https://www.cdc.gov/obesity/data/adult.html>

Pisaneschi, S., Strigini, F. A. L., Sanchez, A. M., Begliuomini, S., Casarosa, E., Ripoli, A., Ghirri, P., ... Simoncini, T. (2012). Compensatory feto-placental upregulation of the nitric oxide system during fetal growth restriction. PLOS ONE, 7, e45294. https://doi.org/10.1371/journal.pone.0045294

Reaven, G. M. (2011). The metabolic syndrome: time to get off the merry-go-round?. Journal of Internal Medicine, 269, 127-136. https://doi.org/10.1111/j.1365-2796.2010.02325.x

Rask-Madsen, C., \& Kahn, C. R. (2012). Tissue-specific insulin signaling, metabolic syndrome, and cardiovascular disease. Arteriosclerosis, Thrombosis, and Vascular Biology, 32, 2052-2059. https://doi.org/10.1161/ATVBAHA.111.241919

Ruidavets, J., Teissedre, P., Ferrières, J., Carando, S., Bougard, G., \& Cabanis, J. (2000). Catechin in the mediterranean diet: vegetable, fruit or wine?. Atherosclerosis, 153, 107-117.

https://doi.org/10.1016/s0021-9150(00)00377-4 
Sarubbo, F., Moranta, D., \& Pani, G. (2018). Dietary polyphenols and neurogenesis: molecular interactions and implication for brain ageing and cognition. Neuroscience and Biobehavioral Reviews, 90, 456-470. https://doi.org/10.1016/j.neubiorev.2018.05.011

Schulz, E., Gori, T., \& Munzel, T. (2011). Oxidative stress and endothelial dysfunction in hypertension. Hypertension Research, 34, 665-673. https://doi.org/10.1038/hr.2011.39

Serino, A., \& Salazar, G. (2018). Protective role of polyphenols against vascular inflammation, aging and cardiovascular disease. Nutrients, 11, 53. https://doi.org/0.3390/nu11010053

Shen, T., Jiang, T., Long, M., Chen, J., Ren, D-M., Wong, P. K., Chapman, E., Zhou, B., \& Zhang D. D. (2015). A curcumin derivative that inhibits vinyl carbamate-induced lung carcinogenesis via activation of the Nrf2 protective response. Antioxidants and Redox Signaling, 23, 651-664. https://doi.org/10.1089/ars.2014.6074

Spahis, S., Borys, J-M., \& Levy, E. (2016). Metabolic syndrome as a multifaceted risk factor for oxidative stress. Antioxidants and Redox Signaling, 26, 445-461. https://doi.org/10.1089/ars.2016.6756

Stephan, B. C. M., Harrison, S. L., Keage, H. A. D., Babateen, A., Robinson, L., \& Siervo, M. (2017). Cardiovascular disease, the nitric oxide pathway and risk of cognitive impairment and dementia. Current Cardiology Reports, 19, 87. https://doi.org/10.1007/s11886-017-0898-y

Umemura, T., Ueda, K., Nishioka, K., Hidaka, T., Takemoto, H., Nakamura, S., Daisuke, J., ... Higashi, Y. (2006). Effects of acute administration of caffeine on vascular function. American Journal of Cardiology, 98, 1538-1541. https://doi.org/10.1016/j.amjcard.2006.06.058

Vona, R., Gambardella, L., Cittadini, C., Straface, E., \& Pietraforte, D. (2019). Biomarkers of oxidative stress in metabolic syndrome and associated diseases. Oxidative Medicine and Cellular Longevity, 19. https://doi.org/10.1155/2019/8267234

Wang, L. E., Lee, W., Cui, Y. R., Ahn, G., \& Jeon, Y. (2019). Protective effect of green tea catechin against urban fine dust particle-induced skin aging by regulation of NF- $\mathrm{BB}$, AP-1, and MAPKs signaling pathways. Evnvirontal Pollution, 252, 1318-1324. https://doi.org/10.1016/j.envpol.2019.06.029

Wu, M-Y., Yiang, G-T., Lai, T-T., \& Li, C-J. (2018). The oxidative stress and mitochondrial dysfunction during the pathogenesis of diabetic retinopathy. Oxidative Medicine and Cellular Longevity, 2018, 3420187-3420187. https://doi.org/10.1155/2018/3420187

Xiangxin, L., Qinlu, L. Zhaopeng, S. Jianping, X., Zhiliang, S., \& Chao, T. (2002). Effect of catechin and epicatechin on serum lipid level in mice. Journal of Henan Agricultural University, 28, 232-233.

Yashin, A., Yashin, Y., Wang, J. Y., \& Nemzer, B. (2013). Antioxidant and antiradical activity of coffee. Antioxidants (Basel), 2, 230-245. https://doi.org10.3390/antiox2040230

Yates, K. F., Sweat, V., Yau, P. L., Turchiano, M. M., \& Convit, A. (2012). Impact of metabolic syndrome on cognition and brain. Arteriosclerosis, Thrombosis and Vascular Biology, 32, 2060-2067. https://doi.org/10.1161/ATVBAHA.112.252759

Youn, Y., Jeon, S-H., Jin, H-Y., Che, D. N., Jang, S., \& Kim, Y-S. (2019). Chlorogenic acid-rich solanum melongena extract has protective potential against rotenone-induced neurotoxicity in PC-12 cells. Journal of Food Biochemistry, 0, e12999. https://doi.org/10.1111/jfbc.12999

Yuyun, M. F., Ng, L. L., \& Ng, G. A. (2018). Endothelial dysfunction, endothelial nitric oxide bioavailability, tetrahydrobiopterin, and 5-methyltetrahydrofolate in cardiovascular disease. Where are we with therapy?. Microvascular Research, 119, 7-12. https://doi.org/10.1016/j.mvr.2018.03.012

Zalba, G., Beaumont, F. J., San Jose, G., Fortuno, A., Fortuno, M. A., \& Diez, J. (2001). Is the balance between nitric oxide and superoxide altered in spontaneiously hypertensive rats with endothelial dysfunction? Nephrology, Dialysis, Transplantation, 16, 2-5. https://doi.org/10.1093/ndt/16.suppl_1.2

Zhou, B., \& Tian, R. (2018). Mitochondrial dysfunction in pathophysiology of heart failure. Journal of Clinical Investigation, 128, 3716-3726. https://doi.org/10.1172/JCI120849 


\section{Copyrights}

Copyright for this article is retained by the author(s), with first publication rights granted to the journal.

This is an open-access article distributed under the terms and conditions of the Creative Commons Attribution license (http://creativecommons.org/licenses/by/4.0/). 